\title{
Ocorrência de anticorpos anti-Toxoplasma gondii em caprinos do semiárido baiano*
}

\section{Occurrence of antibodies to Toxoplasma gondii in the Bahia semi-arid goats}

Geyanna Dolores Lopes Nunes, ${ }^{* *}$ Francilene Silva Santos, ${ }^{* *}$ Rogério Fernando de Jesus, ${ }^{* *}$ Magali Maria dos Anjos Pinto Sampaio, ${ }^{* *}$ Farouk Zacharias, ${ }^{* * *}$ Márcia Cristina Aquino Teixeira, ${ }^{* \star *}$ Fernanda Washington De Mendonça-Lima****

\begin{abstract}
Resumo
Este trabalho teve como objetivo avaliar a frequência de anticorpos lgG específicos contra Toxoplasma gondii em caprinos pertencentes a algumas cidades do semiárido baiano, através do ELISA (ensaio imunoadsorvente ligado à enzima) indireto. Primeiramente, foi realizado um estudo piloto com 49 caprinos para comparar os resultados do ELISA com a RIFI (reação de imunofluorescência indireta) para detecção de anticorpos séricos contra T. gondii. Foram observados 30,6\% (15/49) de soropositivos pelo ELISA, enquanto pela RIFI houve 40,8\% (20/49) de caprinos reagentes. Desta maneira, o ELISA apresentou $70 \%$ de sensibilidade e $96,5 \%$ de especificidade. Em seguida, foram analisadas amostras de soros de caprinos provenientes das cidades de Casa Nova, Curaçá, Jaguarari, Juazeiro, Sento Sé e Uauá. Dentre os 375 animais avaliados, 25,1\% apresentaram títulos de IgG positivos no ELISA para $T$. gondii. As fêmeas tiveram um risco 1,236 vezes maior de serem soropositivas em relação aos machos. Não houve relação entre idade e presença de anticorpos anti- $T$. gondii nestes animais. A cidade com maior número de caprinos soropositivos foi Sento Sé, com 46,4\% (39/84) e a menor frequência foi observada em Juazeiro, com 3,6\% (2/55). Os resultados deste estudo confirmam que a infecção pelo T. gondii é comum em caprinos brasileiros do estado da Bahia, inclusive na região de clima semiárido, considerada mais desfavorável à transmissão.
\end{abstract}

Palavras-chave: diagnóstico, ensaio de imunoadsorção enzimática, pequenos ruminantes, toxoplasmose.

\begin{abstract}
The objective of this study was to evaluate the frequency of specific IgG antibodies against Toxoplasma gondii in goats belonging to some cities of Semi-Arid region of Bahia, by indirect ELISA (enzyme linked immunonosorbent assay). First, a pilot study was conducted with 49 goats to compare results from ELISA with those obtained by IFAT (indirect fluorescent antibody test) to detect serum antibodies against $T$. gondii. It was observed $30.6 \%$ (15/49) of seropositive by ELISA, while the IFAT showed 40.8\% (20/49) reagents goats. Thus, ELISA showed $70 \%$ sensitivity and $96.5 \%$ specificity. Then, sera samples of goats from the cities Casa Nova, Curaçá, Jaguarari, Juazeiro, Sento Sé and Uauá were analyzed. Among the 375 evaluated animals, $25.1 \%$ had positive IgG titers in ELISA for T. gondii. Females have a 1.236 times higher risk of being seropositive compared to males. There was no correlation between age and the presence of anti-T. gondii antibodies in these animals. The city with the biggest number of seropositive goats was Sento Sé, with 46.4\% (39/84) and the lowest rate was observed in Juazeiro, with 3.6\% (2/55). The results of this study confirm that T. gondii infection is common in goats from the semi-arid climate region of Bahia, which is considered adverse for transmission.
\end{abstract}

Keywords: diagnosis, enzyme-linked immunosorbent assay, small ruminants, toxoplasmosis.

\section{Introdução}

As regiões semiáridas constituem cerca de 15\% das terras do mundo (Millennium Ecosystem Asessment, 2005). No Brasil, o semiárido destaca-se por abranger quase $80 \%$ da área do Nordeste, caracterizado pela vegetação Caatinga e por precipitações médias anuais entre 250 e 500 mm (Cirilo, 2008). Neste âmbito, a criação de caprinos apresenta grande importância para o desenvolvimento socioeconômico do semiárido, uma vez que são animais com boa adaptabilidade ao clima desta região (Sousa Júnior et al., 2008; Silva et al., 2010).

O Nordeste do país detém 8,7 milhões de caprinos, correspondendo a $91,4 \%$ do rebanho nacional, sendo o estado da Bahia o detentor do maior percentual de animais (28\%) (IBGE, 2014). A carne e o leite caprino representam uma das maiores fontes de proteína animal para os agricultores e os habitantes das cidades pequenas do Nordeste, bem como fonte de renda, através da venda de couro e do excedente de carne (Oliveira e Albuquerque, 2008). Sousa (2007) relata ainda que existe uma demanda de mercado potencial para a carne caprina, tanto no Brasil quanto no exterior.

Entretanto, grandes prejuízos à caprinocultura são causados por enfermidades infecciosas e parasitárias (Oliveira e Albuquerque, 2008). Toxoplasma gondii, um protozoário formador de cistos teciduais, é considerado uma das principais causas de abortamento por infecção em caprinos, gerando graves perdas

*Recebido em 14 de setembro de 2015 e aceito em 8 de fevereiro de 2017.

**Universidade Federal da Bahia; Escola de Medicina Veterinária e Zootecnia; Pós-Graduação em Ciência Animal nos Trópicos; Salvador; Bahia; Brasil.

***Empresa Baiana de Desenvolvimento Agrícola; Salvador; Bahia; Brasil.

****Universidade Federal da Bahia; Faculdade de Farmácia; Salvador; Bahia; Brasil.

Autor para correspondência: geyannanunes@hotmail.com. 
econômicas (Dubey, 2010). Além disso, constitui um problema de saúde pública, uma vez que pode ocorrer a transmissão para o ser humano se este ingerir carne ou leite de animais infectados (Skinner et al., 1990; Dubey et al., 2014).

Os pequenos ruminantes desenvolvem níveis muito elevados de anticorpos IgG anti- $T$. gondii durante a infecção aguda, os quais podem persistir por anos, na fase de latência (Vitor et al., 1999; Dubey, 2009). Existem vários métodos sorológicos para a detecção destes anticorpos específicos. Em diferentes rebanhos caprinos do estado da Bahia, já foi observada soroprevalência de $28,9 \%$ utilizando-se o teste de aglutinação em látex - LAT (Pita Gondim et al., 1999) e 16,4\% através da reação de imunofluorescência indireta - RIFI (Uzêda et al., 2004). Outra técnica, que pode ser utilizada com grande eficiência, é o ensaio de imunoadsorção enzimática - ELISA. Esta técnica oferece resultados quantitativos, eliminando os riscos de leitura subjetiva como a realizada na RIFI, apresenta maior praticidade por usar somente uma diluição de soro e pode ser adequado à automação para dosagem de grande número de amostras (Costa et al., 2008). Assim, o objetivo deste estudo foi verificar a frequência de anticorpos IgG específicos contra Toxoplasma gondii, através de ELISA, em caprinos de algumas cidades do semiárido baiano.

\section{Material e métodos}

Os caprinos do estudo foram provenientes das cidades baianas de Casa Nova, Juazeiro, Curaçá, Sento Sé, Jaguarari e Uauá. Essas cidades foram escolhidas por encontrarem-se na região norte do Sertão Baiano, caracterizadas por clima tropical semiárido, com temperaturas elevadas e baixa pluviosidade (SEI, 2014). Além disso, apresentam um grande efetivo caprino, uma vez que juntas somam um total de 688.670 animais, correspondendo a $28 \%$ do rebanho baiano (IBGE, 2014). As propriedades praticavam criação extensiva de caprinos para corte, com a principal finalidade de subsistência familiar. Os animais eram alimentados à base de vegetação nativa (caatinga) e suplementados com ração e/ou palma na época de seca.

O tamanho da amostra foi determinado com base na estimativa da proporção populacional, utilizando-se a seguinte fórmula (Miot, 2011):

$$
n=\frac{Z_{\alpha / 2}^{2} \cdot p \cdot q}{E^{2}}
$$

$Z \alpha / 2=1,96$ (valor crítico para $95 \%$ de grau de confiança);

$p=30,6 \%$ (proporção de soropositivos do estudo piloto);

$$
\begin{aligned}
& q=1-p(69,4 \%) ; \\
& E=5 \% \text { (margem de erro). }
\end{aligned}
$$

Foi obtido um "n" amostral mínimo de 327 animais. Em cada cidade foram visitadas, de forma aleatória, 5 a 7 propriedades, coletando-se amostras de 10 a 15 animais por propriedade, somando um total de 375 animais. Foram utilizados animais SRD, clinicamente saudáveis e de ambos os sexos. As amostras de sangue periférico foram coletadas através de punção da veia jugular e depois centrifugadas a $1000 \mathrm{~g}$ por 5 minutos para separar o soro, que foi armazenado a $-20^{\circ} \mathrm{C}$ até o momento das análises. Todos os procedimentos com os animais foram realizados em concordância com a Comissão de Ética no Uso de Animais da Escola de Medicina Veterinária e Zootecnia da Universidade Federal da Bahia - UFBA (Protocolo $n^{\circ}$ 24/2013).

Para o diagnóstico sorológico, foi inicialmente produzido antígeno de T. gondii (Uzêda et al., 2004). Taquizoítos da cepa RH foram cultivados a $37^{\circ} \mathrm{C}$ com $5 \%$ de $\mathrm{CO}_{2}$, em monocamadas de células Vero contendo meio RPMI, $5 \%$ de soro equino, antibióticos (10.000 UI de penicilina e $10.000 \mu \mathrm{g}$ de estreptomicina por $\mathrm{mL}$ ) e antimicótico $(25 \mu \mathrm{g}$ de anfotericina B por $\mathrm{mL}$ ) (Sigma-Aldrich Co., St. Louis, MO-USA). Posteriormente estes taquizoítos foram purificados através de filtros de $5 \mu \mathrm{m}$ e lisados em aparelho de ultrassom, na frequência de $40 \mathrm{Hertz}$. A concentração proteica deste antígeno foi dosada em aparelho LabMax240 (Biotécnica Ind. e Com. Ltda., Varginha-MG, Brasil) pelo método Vermelho de Pirogalol-Molibdato.

O ELISA indireto para deteç̧ão de anticorpos IgG anti- $T$. gondii foi baseado na metodologia de Carneiro et al. (2009), com pequenas modificações. As placas de poliestireno de 96 poços foram sensibilizadas com o antígeno bruto de $T$. gondii na concentração de $10 \mu \mathrm{g} / \mathrm{mL}$. O soro de cada caprino foi diluído na proporção de 1:100 em solução de PBS acrescido de Tween $20(0,05 \%)$ e leite desnatado $(0,25 \%)$. Foram utilizados dois controles negativos: o soro de um caprino recém-nascido antes de ingerir colostro e o soro de um caprino adulto considerado negativo pela RIFI (ponto de corte 1:16). Como controle positivo foi usada uma amostra sérica de caprino infectado experimentalmente por $T$. gondii e com sorologia positiva confirmada por RIFI (título 1:256). O conjugado de anticorpo antiFc de IgG caprina ligado a peroxidase (Bethyl Laboratories, Inc., Montgomery, TX- USA) foi diluído 1:5000 em solução de PBSTween 20. Por fim, foi utilizada a seguinte solução de cromógeno e substrato enzimático: $0,02 \mathrm{~g}$ de orto-fenilenodiamina (OPD) e $60 \mu \mathrm{L}$ de $\mathrm{H}_{2} \mathrm{O}_{2}(10 \%)$ em $20 \mathrm{~mL}$ de tampão citrato-fosfato $\left.\mathrm{pH} 5,6\right)$. A densidade óptica (DO) foi mensurada em espectrofotômetro com espectro de luz de entrada em 492nm e saída em 630nm. Para evitar a variação intermicroplacas dos resultados, cada valor de absorvância foi multiplicado por um fator de correção ( $f$ $=1 /$ média das leituras dos soros controle positivo) determinado para cada microplaca.

Um estudo piloto foi realizado utilizando-se soros de 49 caprinos adultos, SRD e de ambos os sexos, pertencentes à pertencentes à Estação Experimental da EBDA, em Jaguarari-BA. Estas amostras foram testadas para comparação pela técnica de ELISA (conforme descrito anteriormente) e pela RIFI, para detecção de IgG anti-T. gondii. Na RIFI, seguiu-se protocolo descrito por Uzêda et al. (2004). Foi utilizado o ponto de corte 1:16 para os soros e o anticorpo anti-lgG caprina conjugado com isotiocianato de fluoresceína (Sigma-Aldrich Co., St. Louis, MO-USA) foi diluído na proporção 1:50. A leitura foi realizada em microscópio de fluorescência com aumento de 400x, sempre pelo mesmo observador.

$\mathrm{Na}$ análise estatística do estudo piloto, a determinação do poder discriminatório do ELISA foi realizada através da curva "Receiver Operating Characteristic" (ROC), utilizando-se o programa GraphPad Prism 5.0 (GraphPad Software, Inc., San Diego, Califórnia, EUA), no qual a sensibilidade e especificidade foram calculadas como uma função de diferentes pontos de corte. Os dados dos 375 animais, provenientes do semiárido baiano, foram avaliados no programa SPSS 21.0 (SPSS Inc., 
Chicago, IL, USA), no qual foi realizada a análise de associação da soropositividade com gênero, idade e localidade, utilizandose o teste do Qui-quadrado $\left(X^{2}\right)$, com nível de significância de $5 \%$. A magnitude da associação foi determinada pela razão de chances, calculando o Odds Ratio (OR), com Intervalo de Confiança (IC) de 95\%.

\section{Resultados e discussão}

No estudo piloto, analisando 49 amostras de caprinos, foram observados $30,6 \%$ (15/49) de animais soropositivos pelo ELISA, enquanto pela RIFI foram detectados 40,8\% (20/49) de caprinos reagentes. Utilizando a RIFI como teste de referência, o ELISA obteve um resultado falso-positivo e seis falso-negativos. Considerando como ponto de corte a densidade óptica de 0,143, o ELISA apresentou $70 \%$ de sensibilidade e $96,5 \%$ de especificidade (Figura 1). A definição do ponto de corte foi feita através da curva ROC, considerando-se a melhor otimização possível dos valores de sensibilidade e especificidade do teste. Aárea calculada sob a curva ROC foi de 0,88 ( $p<0,0001)$. Quanto maior a capacidade do teste em discriminar os animais em soropositivos ou soronegativos, mais a curva se aproximaria do canto superior esquerdo do gráfico, e a área sob a curva seria próxima de 1 (Martinez, 2003).

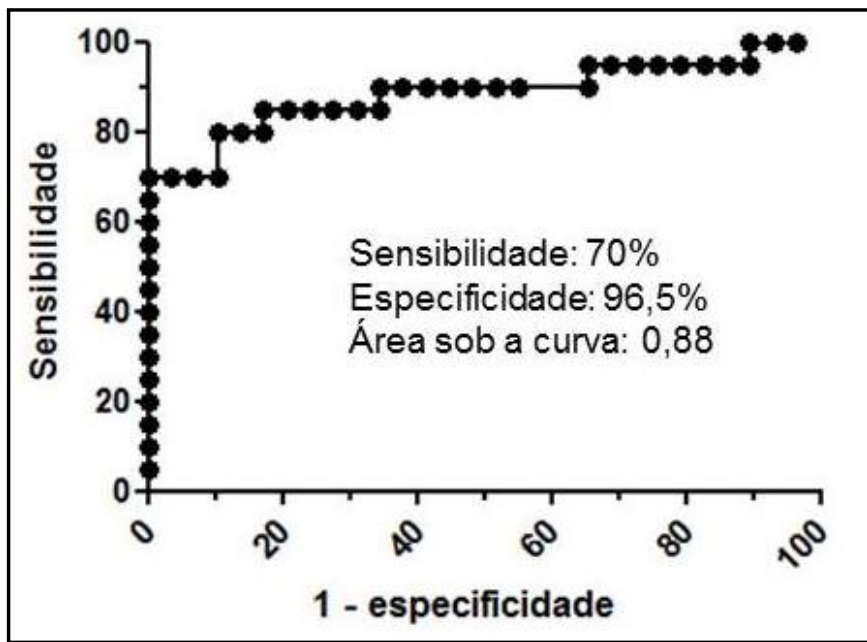

Figura 1: Curva ROC ("Receiver Operating Characteristic") para avaliação da técnica ELISA para detecção de IgG anti-T.gondii, considerando a RIFI como teste padrão. Utilizaram-se amostras de soro de 49 caprinos de Jaguarari-BA como estudo piloto.

O ELISA, seja a base de antígenos brutos, fracionados ou recombinantes, tem sido utilizado para detectar anticorpos anti- $T$. gondii em soros de pequenos ruminantes, geralmente com adequada acurácia (Dubey, 2009). Caballero-Ortega et al. (2008) relataram uma boa correlação entre um ELISA feito com antígeno bruto e o Western blot em 103 ovinos naturalmente expostos, com $91 \%$ das amostras mostrando o mesmo resultado em ambos os testes. A padronização do ELISA é o maior problema porque poucos kits estão disponíveis comercialmente para uso em animais, além de apresentarem elevado custo (Dubey, 2009). Entretanto, foi escolhido realizar o ELISA neste trabalho por este apresentar boa acurácia em relação a outros testes, além de sua adequação à leitura automática (evitando subjetividade pessoal) e possibilidade de realizar a dosagem de um grande número de amostras em uma só placa.

O teste do corante (reação de Sabin-Feldnam) e a RIFI utilizam taquizoítos intactos de $T$. gondii, sendo muitas vezes considerados mais sensíveis e específicos do que a técnica de ELISA porque, durante a infecção, o primeiro aumento significante de IgM e IgG é observado contra antígenos da membrana (Piergili, 2004). Garcia et al. (2012), avaliando a soroprevalência para $T$. gondii em caprinos de Curitiba-PR, também utilizou as técnicas de ELISA e RIFI, considerando este último como teste de referência. Estes autores descreveram um ELISA com elevada sensibilidade $(98,63 \%)$ e especificidade menor $(93,85 \%)$. Variações entre os resultados dos testes sorológicos são comuns, e muito influenciadas pelo método utilizado como padrão para comparação. Quando Shaapan et al. (2008) utilizaram o teste do corante como ensaio de referência para a toxoplasmose em ovinos, o teste de aglutinação modificado - MAT obteve a maior sensibilidade (96\%), seguido pelo ELISA $(90,1 \%)$ e RIFI $(80,4 \%)$. Por outro lado, a RIFI revelou a maior especificidade $(91,4 \%)$, seguido pelo MAT $(88,9 \%)$ e ELISA (85,9\%).

Na avaliação dos 375 animais selecionados no semiárido baiano foram encontrados $25,1 \%(94 / 375)$ de caprinos soropositivos para IgG anti-T. gondii. Com relação ao gênero, foi observada uma frequência de sororreagentes significativamente maior nas fêmeas. Além disso, a OR representa que as fêmeas possuem uma probabilidade 1,236 vezes maior de serem positivas em relação aos machos (Tabela 1). Não houve relação entre idade e presença de anticorpos anti-T. gondii nestes animais.

Tabela 1: Ocorrência de anticorpos IgG anti-Toxoplasma gondii em caprinos do semiárido baiano, distribuídos pelo gênero

\begin{tabular}{lcccc}
\hline Gênero & $\mathbf{N}^{\circ}$ testadas & $\begin{array}{c}\mathbf{N}^{\mathbf{0}} \text { positivos } \\
(\mathbf{\%})\end{array}$ & OR & $\mathbf{9 5 \%}$ IC \\
\hline Machos & 122 & $20(16,4 \%)$ & 0,586 & $0,386-0,891$ \\
Fêmeas & 253 & $74(29,2 \%)$ & 1,236 & $1,077-1,418$ \\
Total & $\mathbf{3 7 5}$ & $\mathbf{9 4}(\mathbf{2 5 , 1 \% )}$ & & \\
\hline
\end{tabular}

$X^{2}=7,242 ; p<0,05$

Vários trabalhos também têm encontrado maior ocorrência de fêmeas caprinas soropositivas para T. gondii do que machos: Silva et al., 2003; Jittapalapong et al., 2005; Teshale et al., 2007; Garcia et al., 2012. Normalmente isto é explicado pelo fato da média de idade dos machos ser menor do que a das fêmeas, uma vez que os machos são abatidos mais cedo enquanto as fêmeas são mantidas por mais tempo no rebanho para reprodução e/ou produção de leite (Garcia et al., 2012). Também já foi mencionado que o manejo diferenciado empregado para reprodutores e matrizes pode influenciar nos resultados (Cavalcante, 2008).

Apesar das cidades e propriedades selecionadas apresentarem características semelhantes de clima, manejo dos animais e finalidade de criação, foram encontradas frequências de caprinos soropositivos significativamente distintas (Tabela 2). 
Tabela 2: Ocorrência de anticorpos IgG anti-Toxoplasma gondii em caprinos do semiárido baiano, distribuídos por município

\begin{tabular}{lcc}
\hline Localidade & $\mathbf{N}^{\circ}$ amostras testadas & $\mathbf{N}^{\circ}$ positivos $(\%)$ \\
\hline Sento Sé & 84 & $39(46,4 \%)$ \\
Jaguarari & 60 & $23(38,3 \%)$ \\
Curaçá & 60 & $16(26,7 \%)$ \\
Casa Nova & 64 & $09(14,1 \%)$ \\
Uauá & 52 & $05(9,6 \%)$ \\
Juazeiro & 55 & $02(3,6 \%)$ \\
Total & $\mathbf{3 7 5}$ & $\mathbf{9 4}(\mathbf{2 5 , 1 \% )}$ \\
\hline
\end{tabular}

$X^{2}=50,294 ; p<0,05$

O percentual total de animais positivos $(25,1 \%)$ encontrado neste trabalho está próximo ao valor relatado por Pita Gondim et al. (1999), que analisaram 439 caprinos na Bahia, dos quais $28,93 \%$ foram positivos. Já no estudo de Uzêda et al. (2004) foi encontrado um valor inferior de animais sororeagentes: $16,4 \%$ (61/373). A utilização de diferentes técnicas sorológicas: LAT (Pita Gondim et al., 1999), RIFI (Uzêda et al., 2004) e ELISA (presente estudo), não permitem uma adequada comparação entre os trabalhos que avaliaram a soroprevalência em caprinos na Bahia. Entretanto, alguns estudos para detecção de anticorpos contra $T$. gondii em caprinos têm mostrado que estes testes podem apresentar resultados similares: $42,8 \%$ (ELISA) e $45,8 \%$ (RIFI) de animais soropositivos em Minas Gerais (Carneiro et al., 2009); 39,5\% (ELISA) e 36,05\% (RIFI) no Paraná (Garcia et al., 2012); 19,5\% (em ambos ELISA e RIFI) em Minas Gerais (Figueiredo et al., 2001); e 32,4\% (LAT) e 33,5\% (RIFI) na Nova Zelândia (Opel et al., 1991).

A frequência da infecção por $T$. gondii em pequenos ruminantes pode ser diretamente influenciada por diferenças de manejo e clima. Estas diferenças existem consideravelmente no estado da Bahia, que possui grande dimensão geográfica e diversidade cultural. Dentre os animais analisados por Pita Gondim et al.
(1999), se considerarmos somente aqueles pertencentes à região de Caatinga baiana, foi encontrado um valor inferior de soroprevalência: 7,27\% (12/165). A menor prevalência de $T$. gondii em áreas de clima quente e seco pode estar relacionada com um ambiente com reduzida contaminação por oocistos, seja pela menor viabilidade da forma infectante do parasito frente às condições ambientais e/ou devido à menor densidade de população humana e animais de estimação, incluindo os gatos (Dubey, 1998; Figliuolo et al., 2004; Pita Gondim et al., 1999). Por exemplo, Anderlini et al. (2011) observaram menor soroprevalência em caprinos criados na região do sertão $(18,2 \%)$ do que na área leste costeira $(66,2 \%)$ de Alagoas. Um clima úmido, costeiro e tropical, com temperatura média anual em torno de $25^{\circ} \mathrm{C}$, seria mais propício para a manutenção de oocistos de T. gondii (Silva et al., 2003; Anderlini et al., 2011).

Quanto ao sistema de criação, a forma de regime extensiva, particularmente se associada com pobres condições socioeconômicas locais, permite contato entre caprinos e oocistos, aumentando a probabilidade de infecção (Cavalcante et al., 2008; Neto et al., 2008; Anderlini et al., 2011). Estas condições foram encontradas na região do semiárido baiano selecionada para o estudo, o que pode favorecer maiores índices de animais sororreagentes ao $T$. gondii. Todas as variáveis mencionadas acima, sobre clima e manejo, podem estar implicadas a exposição dos caprinos à infecção pelo T. gondii, e consequentemente, nas diferenças de soroprevalência encontradas no nosso estudo, de acordo com a localidade avaliada.

\section{Conclusões}

Foi encontrada uma elevada frequência de anticorpos antiToxoplasma gondii $(25,1 \%)$ nos caprinos do semiárido baiano. A técnica de ELISA mostrou elevada especificidade, praticidade de execução e maior rapidez para um grande número de amostras. A importância da toxoplasmose para a produção de caprinos nesta região ainda deve ser determinada, sendo necessário investigar o impacto desta infecção como possível causa de abortamentos e o seu papel como fonte de transmissão para a população humana.

\section{Agradecimentos}

Os autores agradecem ao Fundo de Desenvolvimento Científico e Tecnológico - FUNDECI do Banco do Nordeste e à Fundação de Amparo à Pesquisa do Estado da Bahia - FAPESB pelo suporte financeiro; à Empresa Baiana de Desenvolvimento Agrícola - EBDA, pelo apoio nas coletas de sangue dos caprinos; e ao Grupo de Pesquisas de Protozoários Coccídeos da UFBA, sob responsabilidade do Prof. Dr. Luís Fernando Pita Gondim, pelo apoio e concessão das amostras de taquizoítos de Toxoplasma gondii.

\section{Referências}

ANDERLINI, G.A.; MOTA, R.A.; FARIA, E.B.; SAMICO, E.F.T.; CAVALCANTI, F.; VALENÇA, R.M.B.; PINHEIRO JÚNIOR, J.W.; ALBUQUERQUE, P.P.F.; SOUZA NETO, O.L. Occurrence and risk factors associated with infection by Toxoplasma gondii in goats in the State of Alagoas, Brazil. Revista da Sociedade Brasileira de Medicina Tropical, v. 44, n. 2, p. 157-162, 2011.

CABALLERO-ORTEGA, H.; PALMA, J.M.; GARCÍA MÁRQUEZ, L.J.; GILDO CÁRDENAS, A.; CORREA, D. Frequency and risk factors for toxoplasmosis in ovines of various regions of the State of Colima, Mexico. Parasitology, v.135, p.1385-1389, 2008.
CARNEIRO, A.C.A.V.; CARNEIRO, M.; GOUVEIA, A.M.G.; GUIMARÃES, A.S.; MARQUES, A.P.R.; VILAS-BOAS, L.S.; VITOR, R.W.A. Seroprevalence and risk factors of caprine toxoplasmosis in Minas Gerais, Brazil. Veterinary Parasitology, v.160, p.225-229, 2009.

CAVALCANTE, A.C.R.; CARNEIRO, M.; GOUVEIA, A.M.G.; PINHEIRO, R.R.; VITOR, R.W.A. Risk factors for infection by Toxoplasma gondii in herds of goats in Ceará, Brazil. Arquivos Brasileiros de Medicina Veterinária Zootecnia, v. 60, n. 1, p. 3641, 2008.

CIRILO, J.A. Políticas públicas de recursos hídricos para o semiárido. Estudos Avançados, v. 22, n. 63, p. 61-82, 2008. 
COSTA, T.L.; SILVA, M.G.; AVELAR, J.B.; AMARAL, W.N.; AVELINO, M.M.; CASTRO, A.M. Toxoplasma gondii: toxoplasmose, com ênfase no diagnóstico. Revista de Patologia Tropical, v.37, n.3, p.191-207. jul.-set. 2008.

DUBEY, J.P. Toxoplasma gondii oocyst survival under defined temperatures. Journal of Parasitology, v. 84, p. 862-865, 1998.

DUBEY, J.P. Toxoplasmosis in sheep - The last 20 years. Veterinary Parasitology, v.163, p.1-14, 2009.

DUBEY, J.P. Toxoplasmosis of animals and humans. 2. ed. CRC Press: Boca Raton, 2010. 336 p.

DUBEY, J.P.; VERMA, S. K.; FERREIRA, L. R.; OLIVEIRA, S.; CASSINELLI, A. B.; YING, Y.; KWOK, O. C. H.; TUO, W.; CHIESA, O. A.; JONES, J. L. Detection and survival of Toxoplasma gondii in milk and cheese from experimentally infected goats. Journal of Food Protection, v.77, n.10, p.17471753, 2014.

FIGLIUOLO, L.P.C.; KASAI, N.; RAGOZO, A.M.A.; DE PAULA, V.S.O.; DIAS, R.A.; SOUZA, S.L.P.; GENNARI, M. Prevalence of anti-Toxoplasma gondii and anti-Neospora caninum antibodies in goat from São Paulo State, Brazil. Small Ruminant Research, v. 55, p. 29-32, 2004

FIGUEIREDO, J.F.; SILVA, D.A.O.; CABRAL, D.D.; MINEO, J.R. Seroprevalence of Toxoplasma gondii infection in goats by the Indirect Haemagglutination, Immunofluorescence and Immunoenzymatic Tests in the region of Uberlândia, Brazil. Memórias do Instituto Oswaldo Cruz, v. 96, n. 5, p. 687-692, 2001.

GARCIA, G.; SOTOMAIOR, C.; NASCIMENTO, A.J.; NAVARRO, I.T.; SOCCOL, V.T. Toxoplasma gondii in goats from Curitiba, Paraná, Brazil: risks factors and epidemiology. Revista Brasileira de Parasitologia Veterinária, v. 21, n. 1, p. 42-47, 2012.

IBGE - Instituto Brasileiro de Geografia e Estatística. Produção da Pecuária Municipal. Rio de Janeiro, 2014, v. 41, 108 p. Disponível em: www.sidra.ibge.gov.br. Acesso em: 20 de Agosto de 2016.

JITTAPALAPONG, S.; SANGVARANOND, A.; PINYOPANUWAT, N.; CHIMNOI, W.; KHACHAERAM, W.; KOIZUMI, S.; MARUYAMA, S. Seroprevalence of Toxoplasma gondii infection in domestic goats in Satun Province. Thailand. Veterinary Parasitology, v. 127, p.17-22, 2005.

MARTINEZ, E.Z.; LOUZADA-NETO, F.; PEREIRA, B.B. A curva ROC para testes diagnósticos. Cadernos Saúde Coletiva, v.11, n.1; p. 7-31, 2003.

Millennium Ecosystem Asessment. Ecosystems and human wellbeing: desertification synthesis. Washington DC: World Resources Institute, 2005. Disponível em: http://www.maweb.org/ documents/document.355.aspx.pdf. Acesso em: 20 de fevereiro de 2015.

MIOT, H. A. Tamanho da amostra em estudos clínicos e experimentais. Jornal Vascular Brasileiro, v.10, n. 4, p. 275-278. 2011.

NETO, J.O.A.; AZEVEDO, S.S.; GENNARI, S.M.; FUNADA, M.R.; PENA, H.F.J.; ARAÚJO, A.R.C.P. Prevalence and risk factors for anti-Toxoplasma gondii antibodies in goats of the Serido Oriental microregion, Rio Grande do Norte state, Northeast region of Brazil. Veterinary Parasitology, v.156, p. 329-332, 2008.
OLIVEIRA, E.L.de; ALBUQUERQUE, F.H.M.A.R.de. Manejo sanitário de pequenos ruminantes. Sobral: Embrapa Caprinos e Ovinos, 2008. 27 p.

OPEL, U.; CHARLESTON, W.A.G.; POMROY, W.E.; ROMMEL, $M$. A survey of the prevalence of Toxoplasma infection in goats in New Zealand and a comparison of the latex agglutination and indirect fluorescence tests. Veterinary Parasitology, v. 40, n. 4, p.181-186, 1991.

PIERGILI, F.D. Problems and limitations of conventional and innovative methods for the diagnosis of Toxoplasmosis in humans and animals. Parassitologia, v. 46, n. 1, p.177-181, 2004.

PITA GONDIM, L.F..; BARBOSAJR. H.V.; RIBEIRO FILHO, C.H.A.; SAEKI, H. Serological survey of antibodies to Toxoplasma gondii in goats, sheep, cattle and water buffaloes in Bahia State, Brazil. Veterinary Parasitology, n.82, p.273-276, 1999.

SEI - Superintendência de Estudos Econômicos e Sociais da Bahia. Estatísticas dos Municípios Baianos - Território de Identidade $n^{\circ} 10$ e $n^{\circ} 25$. Salvador: SEI, 2014, 182 p. Disponível em: http://www.sei.ba.gov.br. Acesso em: 03 de Setembro de 2015.

SHAAPAN, R.M.; EL-NAWAWI, F.A.; TAWFIK, M.A.A. Sensitivity and specificity of various serological tests for the detection of Toxoplasma gondii infection in naturally infected sheep. Veterinary Parasitology, v.153, p.359-362, 2008.

SILVA, A.V.; CUNHA, E.V.P.; MEIRELES, L.R.; GOTTSCHALK, S.; MOTA, R.A.; LANGONI, H. Toxoplasmose em ovinos e caprinos: estudo soroepidemiológico em duas regiões do Estado de Pernambuco, Brasil. Ciência Rural, v.33, n.1, p.115-119, 2003.

SILVA, E.M.N.; SOUZA, B.B.; SOUSA, O.B.; SILVA, G.A.; FREITAS, M.M.S. Avaliação da adaptabilidade de caprinos ao Semiárido através de parâmetros fisiológicos e estruturas do tegumento. Revista Caatinga, v. 23, n. 2, p.142-148, 2010.

SKINNER, L.J.; TIMPERLEY, A.C.; WIGHTMAN, D.; CHATTERTON, J.M.W.; HO-YEN, D.O. Simultaneous diagnosis of toxoplasmosis in goats and goatowner's family. Scandinavian Journal of Infectious Diseases, v.22, p.359-361, 1990.

SOUSA, W.H. O agronegócio da caprinocultura de corte no Brasil. Tecnologia \& Ciência Agropecuária, v.1, n.1, p. 51-58, 2007.

SOUSA JÚNIOR, S.C.; MORAIS, D.A.E.F.; VASCONCELOS, A.M.; NERY, K.M.; MORAIS, J.H.G.; GUILHERMINO, M.M. Características Termorreguladoras de Caprinos, Ovinos e Bovinos em Diferentes Épocas do Ano em Região Semi-Árida. Revista Científica de Produção Animal, v.10, n.2, p.127-137, 2008.

TESHALE, S.; DUMÉTRE, A.; DARDE, M.L.; MERGA, B.; DORCHIES, P. Serological survey of caprine toxoplasmosis in Ethiopia: prevalence and risk factors. Parasite, v.14, p.155-159, 2007.

UZÊDA, R.S.; FERNÁNDEZ, S.Y.; JESUS, E.E.V.; PINHEIRO, A.M.; AYRES, M.C.C.; SPINOLA, S.; BARBOSA JÚNIOR, H.V.; ALMEIDA, M.A.O. Fatores relacionados à presença de anticorpos IgG anti-Toxoplasma gondii em caprinos leiteiros do Estado da Bahia. Revista Brasileira de Saúde e Produção Animal, v.5, n.1, p.1-8, 2004.

VITOR, R.W.A.; FERREIRA, A.M.; FUX, B. Antibody response in goats experimentally infected with Toxoplasma gondii. Veterinary Parasitology, v.81, p. 259-263, 1999. 